\title{
Francesca De Cesare y Maria Alessandra Giovannini (eds.), Lenguajes de la política. Más allá de las palabras, Nápoles, UniorPress/ Università degli studi di Napoli 'L'Orientale', 2019, 296 pp.
}

\author{
Marilcia Di Paolo \\ Universidad de Nápoles, Italia
}

Cita sugerida: Di Paolo, M. (2020). [Revisión del libro Lenguajes de la politica. Más allá de las palabras por F. De Cesare y M. A. Giovannini (eds.)]. Olivar, 20(32), e089. https://doi.org/10.24215/18524478e089

El volumen Lenguajes De La Política. Más Allá De Las Palabras, publicado por UniorPress y editado por Francesca De Cesare y Maria Alessandra Giovannini, es una colección de contribuciones sobre las diferentes declinaciones del lenguaje político en discursos directa o indirectamente relacionados con declaraciones, acontecimientos, eventos y cualquier tipo de manifestación o producción de marco político.

En la transición hacia la segunda década del siglo XXI, el panorama político internacional aparece cada vez más variable y fragmentado, por lo que ya no se puede hablar de lenguaje político como género lingüístico y literario único, sino más bien de varios y variados lenguajes políticos; esos lenguajes están hoy presentes en todo tipo de comunicación política institucional o informal, afectando y marcando profundamente la construcción de ideologías y contra-ideologías a nivel local, nacional o internacional.

Este libro pluralista se compone de dos partes: la primera, centrada en el análisis lingüístico de los discursos políticos más o menos recientes en español o, en sentido comparativo, considerando también otras lenguas; la segunda, dedicada a la producción literaria o artística del pasado al presente, amplía aún más los campos de aplicación del discurso político, elaborando sus numerosas posibilidades expresivas, sus estrategias comunicativas y sus efectos a nivel ideológico sobre el pensamiento común.

El artículo de Paul Danler (Universität de Innsbruck) analiza la metáfora y la metonimia en el discurso político como imágenes de un lenguaje figurado, tal vez más eficaz que las palabras mismas, por su capacidad 
de "transmitir global e instantáneamente contenidos incluso muy complejos" (infra, p.19). De hecho, se plantea la idea de que ambas son herramientas no solo lingüísticas, sino también conceptuales, porque establecen nuevas fronteras de comprensión de la realidad y provocan sensaciones hasta corporales en el oyente, lo que justifica el abundante uso de metáforas y metonimias en los discursos políticos tradicionales hasta nuestros días. Danler ofrece un interesante análisis de los varios tipos de metáforas existentes (estructurales, ontológicas y orientacionales) con ejemplos puntuales del discurso político que Fidel Castro pronunció el uno de enero de 1959 en ocasión del cumplimiento de la revolución cubana. De esa manera, el autor logra demostrar cómo, de acuerdo con Paul Chilton, "la metáfora no forma simplemente parte del discurso político, sino que 'hace' política ya que es una herramienta ejemplar de persuasión" (infra, p.22). Puesto que entender significa 'tener un mundo a su disposición', los conceptos metonímicos nos permiten conceptualizar una cosa a través de su relación con otra de manera libre e impredecible. Los hechos abstractos y las imágenes representados por las palabras consiguen acercar el emisor al receptor, finalizando la función persuasiva del discurso político, y llevando "valores añadidos [que] influyen en la percepción de los hechos" (infra, p. 31)

También Luisa A. Messina Fajardo (Università di Roma Tre), observa la metáfora como marco distintivo del discurso político contemporáneo, evidenciando su intento persuasivo y sus peculiaridades en diez discursos llevados a cabo por personalidades políticas internacionales, como Raúl Castro y Hugo Chávez, Zapatero y Aznar, entre otros. Todos los ejemplos considerados se refieren a temas importantes -como la globalización, el medio ambiente, o el terrorismo- y tratan de construir y fortalecer la identidad de cada personalidad o movimiento político. Sobre todo, la contribución de Messina Fajardo evidencia unas características fundamentales de esos discursos, subrayando cómo cada uno de ellos elige sus palabras y metáforas basándose en los contextos sociales y culturales de cada país. En particular, "[l]os políticos viven en contextos diferentes, y son sensibles a los humores de la propia comunidad, por lo cual deben moldear su manera de comunicarse en función de la sensibilidad de la audiencia" (infra, p. 43). Además, la autora señala cómo todos los discursos contemporáneos se destacan por una mayor simplicidad frente a la retórica política tradicional desde los orígenes o, por lo menos, hasta el siglo pasado.

Claudio Grimaldi (Università degli Studi di Napoli “Parthenope”) aborda un estudio del lenguaje político de las crisis y, especialmente de la crisis económico-financiera que afectó al occidente a partir de 2007, fecha del comienzo de la crisis en los EE.UU. A través de un exhaustivo corpus trilingüe (en italiano, francés y español) compuesto de algunos discursos políticos recientes, este artículo hace referencia a la metáfora como marcador esencial de esos discursos y logra analizar los núcleos conceptuales más frecuentes asociados a la terminología de la crisis.

En particular, se analizan 28 discursos políticos de los Jefes de Gobierno y de Estado franceses (8), italianos (10) y españoles (10) en el período 2010-2015, con atención a los fragmentos textuales que tratan del tema de la crisis; la primera parte incluye discursos transmitidos en vivo o por la televisión; la segunda parte incluye los discursos presentados por distintas figuras políticas en ocasiones específicas. Los discursos considerados son básicamente evocativos y tienen doble función: por un lado, subrayar los esfuerzos nacionales frente a la crisis a través de un lenguaje sencillo y libre de términos técnicos; por el otro, responder a la crisis de confianza pública en las instituciones políticas y en el futuro. Finalmente, otro subcorpus observa las consecuencias de las decisiones de la UE hacia la crisis sobre la economía interna de cada país.

La argumentación y las estrategias persuasivas del informe a la nación del presidente de Ecuador Lenín Moreno (mayo 2018) son objeto de estudio de Rosaria Minervini (Università degli Studi di Salerno). La autora observa: "[1]a persuasión requiere que se establezca una relación que es incluso de tipo emocional entre el emisor del mensaje, el político, y su destinatario, el ciudadano" (infra, p.65). De hecho, Minervini presenta un análisis cualitativo sobre las estrategias discursivas que se emplean en las interacciones sociales y que sirven de base para la metodología del Análisis Crítico del Discurso, con el propósito de demostrar cómo las intenciones del emisor contribuyen a construir las ideologías dominantes. 
El discurso examinado, un informe sobre las actividades del Gobierno, posee las características típicas de la mayoría de los discursos en este sector, es decir: la finalidad persuasiva, el lenguaje connotativo y argumentativo, con el objetivo de "influir más que informar". Muy interesante es el enfoque dado por el ACD, que considera la relación profunda entre lengua y estructura social, y señala los efectos que esos discursos pueden tener en la percepción de la realidad.

El innovativo artículo de Laura Mariottini (Università di Roma "La Sapienza"), "Políticas lingüísticas y migración latinoamericana en Roma: mono y plurilingüismo en los signos comunicativos del espacio público", emplea la línea teórica del Linguistic Landscape para describir la visibilidad y el impacto de la comunidad latinoamericana en la ciudad de Roma. La investigación aborda un examen de los signos comunicativos (textos verbales en combinación con otros códigos de comunicación) en los mensajes públicos de Roma, una de las ciudades italianas con la mayor presencia de inmigrantes latinoamericanos. El lenguaje analizado aparece marcado por conmistiones e hibridaciones lingüísticas de tipo diferente, señal de unas "prácticas de (re)territorialización y de apoderamiento del espacio público de Roma" por los residentes latinoamericanos.

A través del Linguistic Landscape o paisaje lingüístico, Mariottini presenta una colección de anuncios de alquiler, letreros comerciales, avisos de eventos artísticos y musicales, etc. en algunos barrios o zonas de la ciudad; el paisaje lingüístico aparece como plurilingüe, ya que la misma comunidad se configura como transnacional, aunque con vínculos fuertes con cada país de origen. Como las metáforas analizadas en los otros artículos de este libro, la lengua española sirve aquí, por lo menos en la mayoría de los casos considerados, para afirmar y construir las identidades personales y comunitarias de los ciudadanos latinoamericanos en Roma.

Jacopo Varchetta (Università degli Studi di Napoli “Parthenope”) focaliza su análisis en el discurso político de las declaraciones de los movimientos indígenas en países como Nicaragua, Bolivia, México, Guatemala, y Ecuador. Esos movimientos, también llamados 'despertar indígena', permiten hoy a los indígenas tomar parte en el cambio social y político del contexto latinoamericano. Tomando como presupuesto el importante reconocimiento de que "[e]s en el momento en que el movimiento indígena toma conciencia de sí mismo en cuanto actor social, que dicho movimiento comienza a elaborar y desarrollar su discurso propio" (infra, p.117), el autor propone un corpus de algunas declaraciones elaboradas en encuentros indígenas recientes en América Latina, como por ejemplo la declaración de la Cumbre Indígena.

En el corpus, se analizan de manera puntual cuatro marcos principales comunes a los textos del corpus: el 'frame identitario', el 'frame territorial-ambiental', el 'frame étnico-cultural', y el 'frame global-crítico'; en todos ellos, fundamental es el proceso de construcción del 'nosotros' como sujeto del discurso político indígena y personalidad colectiva. Un análisis de las palabras frecuentes y de las concordancias completa el estudio propuesto, del que se vislumbra un panorama abierto al pluralismo cultural y a la integración social en el que las comunidades indígenas reivindican su "derecho a la disparidad y el orgullo de la identidad diferencial".

La inmigración en el discurso político del Front National francés de Marine Le Pen es el tema del estudio de Maria Centrella (Università degli Studi di Napoli “L’Orientale”). Hoy como ayer, el Front National, la organización de referencia de la derecha radical francesa, se destaca por su carácter populista, caracterizado por frecuentes reivindicaciones dirigistas y proteccionistas, y sobre todo antieuropeas, anti-inmigración y anti-musulmanas. A partir de los años 80, el Front National fue guiado (hasta el 2011) por Jean-Marie Le Pen, y después por su hija Marine.

En este trabajo la autora compara algunos elementos del lenguaje del Front National en los discursos de Jean-Marie Le Pen y en aquellos de Marine; en particular, se examina el tema de la inmigración, uno de los sellos distintivos de las derechas populistas europeos, analizando el lenguaje de algunas declaraciones desde un punto de vista léxico, retórico y semántico. Además de seguir los motivos tradicionales de esos movimientos, 
en los que la palabra 'inmigración' se relacionan con los conceptos de desempleo e inseguridad, Marine Le Pen emplea "un léxico económico más amplificado y un nuevo campo semántico ligado a la laicidad".

Como emerge del análisis, la retórica anti inmigración se centra en los discursos de la derecha de Le Pen, aunque ciertos aspectos raciales o de religión se abordan con prudencia a través de estrategias semánticas y argumentativas que, de hecho, amplifican temas políticos ya afirmados. Con la retorsión, Le Pen se apropia de algunas palabras típicamente de la izquierda distanciándolas de su significado original; con la normalización, el discurso "frontista" se hace menos radical y más suave, logrando no solo convertir los mensajes antiinmigración en temas positivos, sino también ampliar la base de receptores de esas ideas.

En el último artículo de la primera sección, Carmen Saggiomo (Università degli Studi della Campania "Luigi Vanvitelli”) observa la política lingüística en Côte d'Ivoire durante y después de la colonización francesa. En cuanto colonia del imperio francés de 1893 hasta 1960, la Côte d'Ivoire estuvo sujeta a una dominación cada vez más violenta y restrictiva, hasta la imposición, entre otras cosas, del francés como única lengua oficial del país. El estudio de Saggiomo tiene como objetivo analizar el proceso de adquisición da lengua francesa frente a la variedad de idiomas locales a través de la enseñanza y la desvalorización de las lenguas y culturas indígenas; también se observa la formación de una interlengua creada por la población colonizada (petit-français o français-tirailleur) como reacción y protesta contra los colonos franceses.

En un segundo momento, la autora evidencia cómo, tras la independencia, la Côte d'Ivoire decidió no rechazar en absoluto el francés, recuperando la lengua "con el objetivo de convertirla en el factor unificador de la nación" con medidas que se preocuparon de la promoción de otros idiomas locales solo a partir de 1977. De hecho, esas decisiones muestran cómo la colonización permaneció en las costumbres lingüísticas y culturales del país africano, lo que todavía constituye una forma de subordinación a la herencia colonial: en este caso, el discurso político aparece en sus consecuencias más destructivas, ya que la dominación ideológica se realiza a través de la lengua del colonizador.

La segunda sección del libro empieza con la intervención de Hugo Bello (Universidad Alberto Hurtado, de Santiago de Chile), cuyo estudio se basa en una somera revisión de la obra cronística de Joaquín Díaz Garcés (1877-1921), publicista, cronista, cofundador y redactor de El Mercurio de Santiago, fundador de la Revista Zig-Zag (1905-1964) y del Pacífico Magazine (1913-1921), tres hitos de la transformación de la prensa en un Chile que, en la primeras décadas del siglo XX, comienza a convulsionar por tensiones políticas y sociales. Dentro de esta red de factores de la transformación moderna de América Latina -que incluye el aumento de la alfabetización, la consolidación económica de la oligarquía, la cristalización de la prensa favorable a la hegemonía de las ideas liberales y mercantilización de un creciente número de esferas de la realidad nacional- se deben juzgar las condiciones que abrirán la crónica hacia formas más modernas de expresión narrativa. La tesis que propone Hugo Bello es que, en una esfera cultural de transformación del mercado de lectores, resulta evidente que lo que cambia es el medio así como la función de la prensa, sus condiciones comunicativas y semióticas; por lo tanto, procura personificar en la figura de Díaz Garcés las transformaciones que caracterizan la constitución del género cronístico, pero con ello también a las contradicciones en el orden político e ideológico que se presentarán como telón de fondo de las crónicas publicadas por este periodista pionero en la articulación de la prensa moderna, a pesar de su ideología reaccionaria.

El punto de partida del estudio de Antonella Cancellier (Università degli Studi di Padova), es la historia del proceso y de la ejecución en los Estados Unidos de dos anarquistas de origen italiano, Nicola Sacco y Bartolomeo Vanzetti, injustamente acusados de dos robos a mano armada y del doble homicidio de un cajero y de un guardia. En los siete años entre el arresto y la ejecución (1920-1927) se desarrolló una imponente movilización internacional por la revisión del proceso que probaba no solo su inocencia, sino también la voluntad de las autoridades estadounidenses de llevar a cabo un gesto de represalia política, debido al terror hacia los radicales y aún más motivado por la fobia xenófoba. La autora analiza dos transposiciones cinematográfica y teatral- de ese célebre caso. 
La coproducción cinematográfica ítalo-francesa Sacco e Vanzetti (1971), dirigida por Giuliano Montaldo presenta una estructura narrativa en armonía con una rigurosa reconstrucción histórica de los sucesos a través del soporte visual de documentos reales, el tono marcadamente popular y la vena melodramática, elementos que fueron decisivos para el estrepitoso éxito internacional del film.

La obra teatral argentina Sacco y Vanzetti. Dramaturgia sumaria de documentos sobre el caso, realizada por Mauricio Kartun (1991), es una excelente reelaboración de materiales documentales donde intersticios de testimonios, historias marginales, fragmentos epistolares, documentos jurídicos, viven una vida nueva y poética.

Laura Durante (Università degli Studi di Napoli “Federico II") focaliza su discurso sobre Mercedes Pinto (1883-1976) que, con su vida y su obra narrativa, poética y periodística, resulta ser el ejemplo perfecto del escritor que, a través de sus circunstancias vitales, descubre los problemas sociales de su tiempo y denuncia las incongruencias de su época. Ella resume el compromiso político de la escritora española en tres apartados que se van perfilando y la acompañan a lo largo de su vida: el compromiso de Mercedes Pinto en relación con la necesidad de una disposición legal que permita el divorcio en España; la creación de instituciones útiles para la formación y la educación permanente durante el exilio en Uruguay; el compromiso de Mercedes Pinto en favor de la igualdad de la mujer, de la educación femenina y la de las clases desfavorecidas, compromiso siempre vigente en ella, pero que se hace patente sobre todo durante su último periodo en México.

El trabajo de Raquel Macciuci (Universidad Nacional de La Plata, Argentina), se propone exponer la razón histórica y el diferente significado del concepto de "desaparecido", en el marco de la guerra civil española por un lado y de las dictaduras del Cono Sur y de la Argentina, en particular por otro. La autora demuestra cómo la selección de un término para designar la realidad no es aleatoria: además de revelar un cambio en percepción del pasado y una reconfiguración de la realidad representada; es un indicio poderoso de la posición política y, a su vez, impulsa nuevas acciones para la gestión de la memoria. Esta consideración constituye el paso previo imprescindible para luego indagar sobre el modo en que la literatura y otros géneros discursivos transmiten la experiencia de la desaparición completando vacíos y contestando a preguntas a las que la historia no puede responder.

Rosa María Grillo (Università degli Studi di Salerno) nos ofrece una interesante historia del género testimonial latinoamericano en la que encontramos voces de 'náufragos' -supervivientes, ex rehenes, ex detenidos, testigos incómodos y/o callados, etc.- que cuentan sus propias vidas y sus propias experiencias para 'des-cubrir' las mentiras del aparato dominante y deconstruir la historia impuesta invirtiendo roles, valores, virtudes y vicios. Entre las múltiples formas del género, la autora privilegia la tipología del 'testimonio periodístico', que se inauguró con Relato de un náufrago de García Márquez de 1955, subrayando una modalidad muy frecuente en este subgénero testimonial: la publicación antes 'por entrega' en algún periódico y luego la 're-generación' en libro, con mayores o menores readaptaciones para llegar a tener una forma y un sentido de unidad, como una novela.

El trabajo de Graciela Goldchluk (Universidad Nacional de La Plata, Argentina) se encuadra en la perspectiva de la crítica genética, es decir del estudio de los procesos de escritura a partir de los manuscritos de autores. En una primera parte, la autora cuestiona las maneras de leer un manuscrito en relación unívoca con el momento histórico de su producción y reclama una lectura atenta a la multiplicidad temporal que implica la escritura. En una segunda parte, su reflexión se centra en el análisis de un manuscrito de Manuel Puig, escritor argentino y autor de novelas que se encuadran en lo que hacia los años setenta se llamaba 'literatura comprometida', pero que, sin embargo, tienen un alto contenido político mucho más evidente hoy que cuando fueron publicadas. La autora pone a prueba sus afirmaciones mediante el análisis de El beso de la mujer araña (1976) preguntándose cómo es posible que una novela protagonizada por un preso político marxista y un homosexual sin conciencia de clase que conviven y aprenden uno del otro en la cárcel, haya sido vista como despolitizada, aunque ese fue el contexto de lectura en la época en que se publicó. 
Emilia Perassi (Università degli Studi di Milano) nos proporciona una interesante reflexión sobre la narrativa testimonial, indudablemente una de las prácticas de memoria más poderosa en la conformación de una cultura del recuerdo. En particular, focaliza su atención en la superación del duelo, individual y colectivo, en los contextos post-dictatoriales del Cono Sur, reivindicando, como afirma Elizabeth Jelin, "la necesidad de 'trabajar' activamente sobre los recuerdos para que la memoria del pasado traumático no se vea obliterada por el silencio y el olvido, ni se convierta en «repetición ritualizada" (infra, p.236). En ese contexto, Perassi propone el análisis de tres novelas de testimonio de segunda generación de autores argentinos Cómo enterrar a un padre desaparecido (2012), de Sebastián Hacher; Una muchacha muy bella (2013), de Julián López; Aparecida (2015), de Marta Dillon que articulan tres opciones enunciativas, respectivamente testimonialidad mediada, ficticia y autobiográfica.

También Maria Alessandra Giovannini (Università degli Studi di Napoli “L’Orientale”) propone reflexiones sobre la narrativa testimonial de segunda generación, una escritura que, para los hijos de militantes políticos bajo la última dictadura argentina, significa la recuperación de una infancia marcada por el trauma y de su propia identidad presente a través de la comprensión, y la consiguiente aceptación, de las razones que llevaron a sus padres a sacrificar su vida y su relaciones familiares por la lucha armada y la clandestinidad. En la novela La casa de los conejos de Laura Alcoba -que decide contar su historia de los meses vividos en clandestinidad junto a su madre en la casa Mariani en La Plata de los años setenta- Giovannini observa las estrategias narrativas a partir de las cuales se ponen en escena un conjunto de ambigüedades y duplicidades. De hecho, los límites de género, siempre re-definibles, entre autobiografía y autoficción, del discurso testimonial, se ve amplificado a través de una serie de dualidades. A la duplicación de la representación del yo autobiográfico entre voz infantil y voz adulta que multiplica la ya natural fragmentación del recuerdo, se añade el bilingüismo de la autora que elige el francés para la narrativización de lo vivido mientras el castellano se convierte en la lengua del trauma.

En su trabajo, Fernando Oscar Reati (Georgia State University, Atlanta, EEUU) se pregunta por la poderosa carga emocional de ciertas palabras e imágenes que, una vez desaparecido el contexto histórico en el que surgieron y del que se dio forma a su sentido, pierden efectividad. Divorciadas de su época, esas ideas fuertes terminan por convertirse -en palabras de Marc Angenot- en un 'vasto cementerio de ideas muertas', Por lo tanto, ¿Cómo entender el pasado según lo vivieron sus actores ahora que no compartimos los mismos códigos? ¿Con qué instrumentos analizar esos lenguajes pasados de la política mientras se estudian los discursos presentes de la memoria? Y a su vez, ¿cuál es la responsabilidad ética y profesional del investigador que fue testigo y parte de aquella época, en la transmisión del aspecto emotivo de la experiencia? Estos son algunos de los interrogantes de Reati, a los que trata de dar respuestas a través de ejemplos de novelas argentinas de la generación 'sándwich' tales como La vida por Perón (2004) de Daniel Guebel, Historia del llanto (2007) de Alan Pauls, Museo de la Revolución (2006) de Martín Kohan, que hacen hincapié en el poder mágico de ciertas palabras y temporalidad efímera.

El volumen resulta ser, por lo tanto, una importante y necesaria oportunidad de reflexión sobre las potencialidades, el valor estratégico y la carga simbólica que ofrece el 'lenguaje de la política en sus diferentes contextos de utilización. 